\title{
Heavy Metals in Soils as Indicator of Sanitary State of Territories: Monitoring of the South of Astrakhan Region
}

\author{
Nikolay Alexandrovich Bogdanov \\ Laboratory of Geomorphology, Institute of Geography of the Russian Academy of Sciences, Moscow, Russia \\ Email address: \\ nabog@inbox.ru

\section{To cite this article:} \\ Nikolay Alexandrovich Bogdanov. Heavy Metals in Soils as Indicator of Sanitary State of Territories: Monitoring of the South of Astrakhan \\ Region. Journal of Health and Environmental Research. Vol. 4, No. 4, 2018, pp. 119-129. doi: 10.11648/j.jher.20180404.11
}

Received: August 27, 2018; Accepted: September 21, 2018; Published: October 19, 2018

\begin{abstract}
The results: 1) long-term monitoring of $\mathrm{Hg}$ concentrations and amounts of metals $\mathrm{Zc}(\mathrm{MnCrVNiCoCuAgZnPbSnMo})$ in the soils of the area of deployment of the Astrakhan gas complex (AGC; stages: 19911997-2007-2012 years); 2) estimates of the dynamics of $\mathrm{Hg}$ in soils of villages in the Volga Delta in the period 1995-2009, Since in the Astrakhan region such significant assessment has been undertaken (detail and coverage areas). At the distance of $50 \mathrm{~km}$ from AGC on the stages of the control 1997-2007-2012 the tendency for the deterioration of the hygienic condition of the land was discovered. In a separate ghosting the contents of $\mathrm{Hg}$ in the soil was up to $285 \mathrm{mg} / \mathrm{kg}$ and was approaching a "target" safe levels $(300 \mathrm{mg} / \mathrm{kg})$ adopted in Western Europe. The content of $\mathrm{Hg}$ in soils to 2007 has increased 6 to 8 times on the leeward of the North-West territories, distant $15 \mathrm{~km}$ from AGC. The study established the effect of concentration of Hg in summer in the surface horizon of soils. When handling Hg-containing (70-100 $\mu \mathrm{g} / \mathrm{kg}$ ) commercial sulfur, a significant role in the deterioration of the hygienic state of the sanitary protection zone belongs to their Eolian distribution of particles from the places of storage, loading and transportation of raw materials. The total number of metals at values $\mathrm{Zc}(\mathrm{MnCrVNiCoCuAgZnPbSnMo})$ as the nearest (sanitary protection - up to $5 \mathrm{~km})$ far $(5-50 \mathrm{~km})$ and background sites has risen steadily. By 2012, a number of places in the AGC-30 km control zone had already recorded hygienically dangerous levels of total accumulation of metals (up to $\mathrm{Zc}=34$ ). The spatial variability of this state is largely controlled by the dispersion of emissions by the prevailing East and South-East winds. In the settlements of the Volga Delta, gasification of boiler houses ensured the dispersion of $\mathrm{Hg}$ in soils ( $>90 \%$ of its previously accumulated amount). Concentrations decreased to almost background values $(20-60 \mu \mathrm{g} / \mathrm{kg})$. Further quality control of the hygienic state of the territories needs to be repeated sampling of soil and involvement of medical statistics on the incidence of residents of the region.
\end{abstract}

Keywords: Hygienic Condition, Diagnostics, Variability, Heavy Metals, Soils, Astrakhan Gas Complex, Settlements of the Volga Delta

\section{Introduction}

Diagnostics relevance of hygienic condition of environment is evident according to variability of $\mathrm{Hg}$ and other cancerogenic heavy metals $(\mathrm{Pb}, \mathrm{Zn}, \mathrm{Ni})$ number in soils. Systematic incoming of these substances into human body even in small doses by inhalation, with food, water and hectically could be a course of lung, skin and digestive tract cancer.

The anomalies of heavy metal (HM) concentrations in the soil indicate the migration and redistribution of pollutants coming from technogenic objects. Foci of high concentrations of pollutants contaminate contiguous media.
The dynamics of the content indicates the variability of the ecological and hygienic state of the lands. Diagnosis of such dynamics is a key moment in the ranking of territories according to the order of the medical and preventative care measures $[1,2]$.

Purpose of research is hygienic condition valuation of lands of various purpose of use with different sources of toxicants using the long-term dynamic of heavy metals concentration in surficial soil horizons.

An example is the results of long-term monitoring of $\mathrm{Hg}$ and other HM (MnCrVNiCoCuAgZnPbSnMo) in soils in the vast territory of the Astrakhan region [3-5] (Figures 1, 2). 


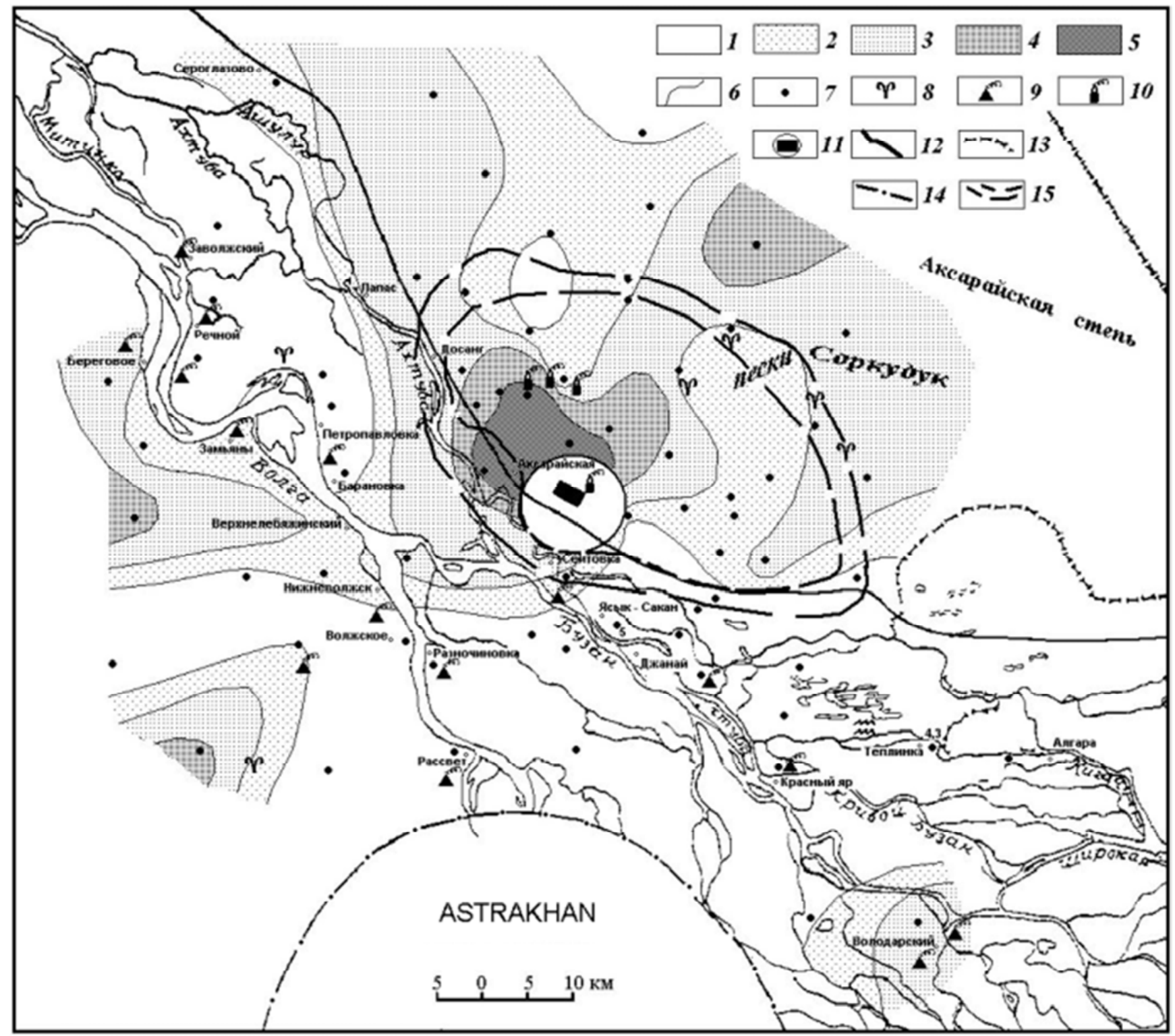

Figure 1. Mercury dynamics in the semidesert soils and Volgo-Ahtubinskaya flood plain of Lower Volga: accumulation-dispersion of concentrations in 1997 $\left(C_{1}\right)$ and $2007\left(C_{2}\right), K c_{10}$.

Dynamics, $\mathrm{Kc}_{10}=\mathrm{C}_{2} / \mathrm{C}_{1}: 1$ (dispersion) $<1(0.07-0.9)$ and 2, 3, 4, 5 (accumulation) - 1-1.5, 1.5-3, 3-6, 6-8, respectively; 6 - accumulation isolines Kc $\mathrm{c}_{10}, 7-$ soil samples collection points, 8 - livestock farms, 9 and 10 - pollutants emission sources: boiler-houses, Astrakhan Gas Complex (AGC) funnels and gas flares, respectively; 11 - AGC, 12 - railroad, 13,14 and 15 - borders: state, Astrakhan suburbs and AGC sanitary protection zone (former $-8 \mathrm{~km}$ and present -5 $\mathrm{km})$, respectively. 


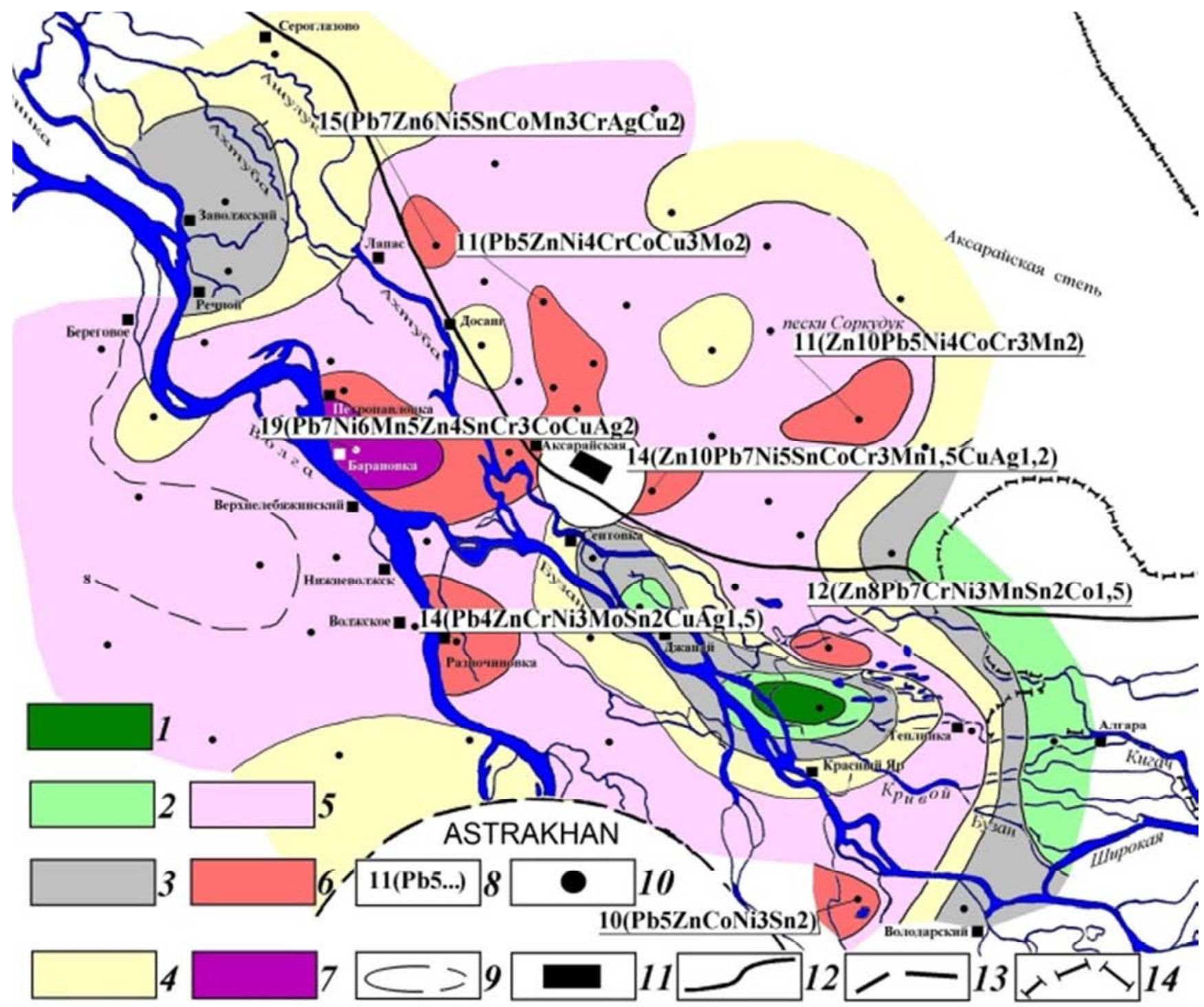

Figure 2. Dynamics of total South Astrakhan Region soils contamination by metals: Zc(MnCrVNiCoCuAgZnPbSnMo), 1997-2007 years period.

1-7 - changing trends: differential $\Delta=$ Zc2007 - Zc1997: 1,2 - self clarification: $-8.6 \div-3,-3 \div 0 ; 3-$ stabilization or slight accumulation: $0-3 ; 4,5,6$ and $7-$ sustained accumulation: $3-6,6-10,10-15$ and 15-19 respectively; 8 - values $\Delta$ (out of brackets) and pollution intensity increase in the terms of relation Zc2007 / Zc1997 >1 (within brackets); 9 - isolines of values $\Delta$, including supposed (dotted line); 10 - soil samples collection points, 1997 and $2007 ; 11$ AGC, 12 - railroad, 13 и 14 - borders of Astrakhan city and Russian boundary, respectively.

The specific character of dry and hot climate $(250 \mathrm{~mm}$ of annual precipitation, evaporative capacity up to $1000 \mathrm{~mm}$ ), soil neutral and alkaline reaction $\mathrm{pH}=7-10$, soil carbonateness and sulphates and chlorides enrichment $(\geq 120 \mathrm{mg} / \mathrm{eq}$, Solonchak soils) promote accumulation of pollutants from the surface, particularly on topographic low. Erosion of polluted soils and dust-storms are dangerous for human health.

\section{Objects and Methods of Research}

\subsection{Objects}

No. 1 - developed and virgin lands in a radius of up to 100 $\mathrm{km}$ from the AGC; No. 2 - urbanized territories of the south of the Astrakhan region; monitoring - the period 1991-2012.

\subsection{Methods}

The variability of the hygienic condition of the region's lands is diagnosed by the dynamics of the microelement composition of soils. Atmospheric streams of metalcontaining vapors and aerosols were traced along the configuration of lithochemical anomalies [1, 4].

At site No. 1, monitoring was carried out in stages - in 1991, 1997, 2007 and 2012 (for 21 years). Samples of soils of 8-16 rays were selected from the surface of the peaks of the hillocks, ridges and in the unsealed areas of the floodplain (layer $0-5 \div 10 \mathrm{~cm}$ ). The radius of the control zone (100 km from AGC, 1991) was reduced to 50 and $30 \mathrm{~km}$ in subsequent monitoring stages (table 1).

According to the standard methods, the gross metal 
content was determined in soil samples: atomic absorption and approximate-semiquantitative spectral atomic emission analysis (for calculating the values of the total pollution index Zc). Samples were analyzed in the certified chemical laboratories.

Total soil contamination by metals was valuated by standard sanitary index $\mathrm{Zc}=\Sigma_{\mathrm{n}}^{\mathrm{i}} \mathrm{Kc}-(\mathrm{n}-1)$, where $\mathrm{Kc}$ is metal concentration criterion in the sample collection point in relation to background $\left(\mathrm{Kc}=\mathrm{C}_{\mathrm{i}} / \mathrm{C}_{\text {background }}\right), \mathrm{n}-$ is metals calculated number [2].
Trends in the dynamics of the state of land in the control points are revealed both by the ratio of the content $(\mathrm{C})$ of individual metals (for example, $\mathrm{Kc10}$ or dynamics of $\mathrm{Hg}$ over 10 years: $\mathrm{Kc}=\mathrm{C}_{2007} / \mathrm{C}_{1997}$ ), and by the difference in the sum of metals in the values of $\mathrm{Zc}$ for the current and the previous monitoring stages $( \pm \Delta \mathrm{Zc}(\mathrm{MnCrVNiCoCuAgZnPbSnMo})=$ $\mathrm{Zc}_{2012}-\mathrm{Zc}_{1997}$ ) [8-10]. The condition of the near (in fact, sanitary-protective zone - SPZ), and the far zones was diagnosed separately (Figures 1-4; table 1, 2).

Table 1. Longterm changes of Hg concentration in the soils of AGC area.

\begin{tabular}{llll}
\hline \multirow{2}{*}{ Year, season } & \multicolumn{4}{l}{ Radius of zone of potential AGC waste influence, km } \\
\cline { 2 - 3 } & $\mathbf{0 - 5}$ & $\mathbf{5 - 5 0}$ & $\mathbf{0 - 5 0}(\mathbf{a v e r a g e )}$ \\
\cline { 2 - 3 } & \multicolumn{2}{l}{ Number: (range) average, mcg/kg } & $(3-150) 10$ \\
\hline 1991, August - September & - & $(4-2285) 56$ & $(4-285) 38$ \\
1997, April & $(4-79) 23$ & 59 samples & 134 samples \\
& 75 samples & $(20-100) 30$ & $(20-120) 50$ \\
2007, June - July & $(20-120) 60$ & 69 samples & 151 samples \\
2012, April & 82 samples & $\leq 20,73$ samples & $\leq 20,98$ samples \\
\hline
\end{tabular}

Dash - no data

Table 2. Dynamics of total soils contamination by metals AGC sanitary protection zone, 1997-2012: Zc(MnCrVNiCoCuAgZnPbSnMo).

\begin{tabular}{|c|c|c|c|c|c|c|}
\hline \multirow{2}{*}{$\mathbf{Z c}$} & \multicolumn{3}{|c|}{ Zc, for the year } & \multicolumn{3}{|c|}{$\pm \Delta \mathrm{Zc}$ : increase(difference $\mathrm{Zc}$ in soil samples for the last years period) } \\
\hline & 1997 & 2007 & 2012 & 10 years $(2007-1997)$ & 5 years $(2012-2007)$ & 15 years $(2012-1997)$ \\
\hline MIN & -3.2 & 0.9 & 4.9 & -0.2 & -5.2 & 0.7 \\
\hline MAX & 12 & 17.1 & 27.4 & 19.1 & 15.5 & 22.1 \\
\hline MID & -0.4 & 5.9 & 9.1 & 6.3 & 3.3 & 9.6 \\
\hline
\end{tabular}

At site No. 2, soil samples were taken from a regular sampling network using the envelope method $(200 \times 200 \mathrm{~m})$.

Since then, this kind of diagnostics with detailed assessments of the state of vast territories has not been carried out in this region.

\section{Results}

As a result of many years of research diagnosed a number of points:

A) In the area of functioning of AGC tendencies of growth of concentrations of $\mathrm{Hg}$ and some other $\mathrm{HM}$ both in the Northwest leeward sector of a sanitary protection zone, and in background territories are revealed;

B) Gasification of populated areas in the Volga river Delta ensured improvement of ecological and hygienic condition of the lands as a result of disappearance of hotbeds with dangerously high concentrations of HM;

C) The current density of the network of soil pollution control points is characterized by insufficient detail.

\section{Discussion of Results}

\subsection{Object No. 1}

Object is the landscapes of the Volga-Akhtuba floodplain and semi-deserts on the banks of the Volga valley, to a different extent. The flood plane is dissected by creeks channels, degradations, ridges, dams. Outcrops of ancient sand dunes and knobs are rarely found. Fertile soils generally have loamy mechanical composition. Pit-and-mount and ridgy (up to 4-8 m) sands blown from ancient salted alluvialmarine deposits, are developed along the Volga valley coasts. Knobs are covered by zonal brown desert-steppe soil and elementary sandy soil on the deflation areas. The general parts of territory are pastures, agricultural lands and virgin lands. Numerous settlements and highways are along the valley coasts, flood plane and Volga delta (Figures 1,2).

Since 1987, near the city of Aksaraysk, the Astrakhan Gas Complex (AGC) has been operating on the gas-condensate field of the same name. Natural gas and toxic gas condensate contain elevated sulfur concentrations (up to $25 \% \mathrm{H} 2 \mathrm{~S}$ ), volatile organic compounds (VOCs) $\mathrm{Hg}$ and other $\mathrm{HM}(\mathrm{Cd}$, $\mathrm{Cu}, \mathrm{Cr}, \mathrm{Ni}, \mathrm{Zn}$, etc.). Heavy metals, in addition to dominant gases (H2S, SOx, NOx), are also present in the emissions of the Astrakhan Gas Processing Plant (AGPP). Liquid wastes of production are pumped into the interior, and solid (sulfur, contains residual $\mathrm{Hg}$ ) and gaseous contact with the environment and in a certain way affect human health. The impact of macrocomponents of emissions of such objects significantly affects the development of dangerous diseases of the circulatory system, respiratory organs, malignant neoplasms, etc. Systematic intake of HM into the human body, even in small doses, inhaled (vapor and aerosol), with food, water and tactile can to cause oncopathology. The overwhelming number of HM causes microelementoses, severe poisoning, dangerous changes in the microelement 
composition of a person and other diseases $[3,6,11]$.

In the sanitary protection zone (SPZ - $5 \mathrm{~km}$ ) there are 1,149 sources of pollutants. They throw 70 varieties of pollutants into the atmosphere. Within a radius of $8 \mathrm{~km}$ from the AGC lived 15 thousand people. The content of macrocomponents of emissions in the ambient air after the launch of the AGPP and in the first decade of operation of the AGC (1980-1990), often exceeded the maximum allowable concentration (MAC). Air pollution was facilitated by frequent stops of the AGPP operation from 24 to 7 cases per year (from 1987 to 1990, respectively). Subfluxing observations of the state of atmospheric air during that period of the work of the AGC (1990) indicate a constant excess of the maximum permissible concentration in air of the $\mathrm{H} 2 \mathrm{~S}$ content in 8-19 times. In the SPZ, hydrocarbon concentrations often reached 1.2-2.6 times the maximum permissible concentration, and maximum one-time to 400 MAC. The morbidity of the respiratory organs at that time sharply increased by a factor of $\sim 2$ (up to 1389 cases with mean values in the region of 727 per 100,000 people, 19841988) $[4,7,8]$.

Improvement of the technology of extraction and processing of raw materials led to a decrease in 2003-2013 of volumes of specific emissions (from 9.1 to $8.9 \mathrm{~kg} /$ thousand $\mathrm{m} 3$ ). Since 2006, there has been a decrease in the death rate of the population both in the zone of the supposed influence of the AGC (with a radius of $\sim 30 \mathrm{~km}$ ) and in the region as a whole. The decrease in mortality was 12.3 people per 1000 people (2013), which was 6.8 and $6.1 \%$ less than in the Southern Federal District and the average for Russia, respectively. Exceeds the MAC of macroelements and VOCs in the air at the boundary of the SPZ in recent years is not observed. In nearby villages, the proportion of soil samples that do not meet the sanitary and chemical standards is only $\leq$ $0.65 \%$ (2012) [4].

However, the causal relationship between the incidence and the trace element composition of the emissions has not been investigated to date. In the vicinity of the AGC, the air control posts monitor only macrocomponents and VOCs [7, 8]. In the absence of such monitoring in the atmosphere, the locations of the concentration of the emission material near the ground and its deposition on the surface can be judged from the ecological and geochemical condition of the soil [1, $2]$.

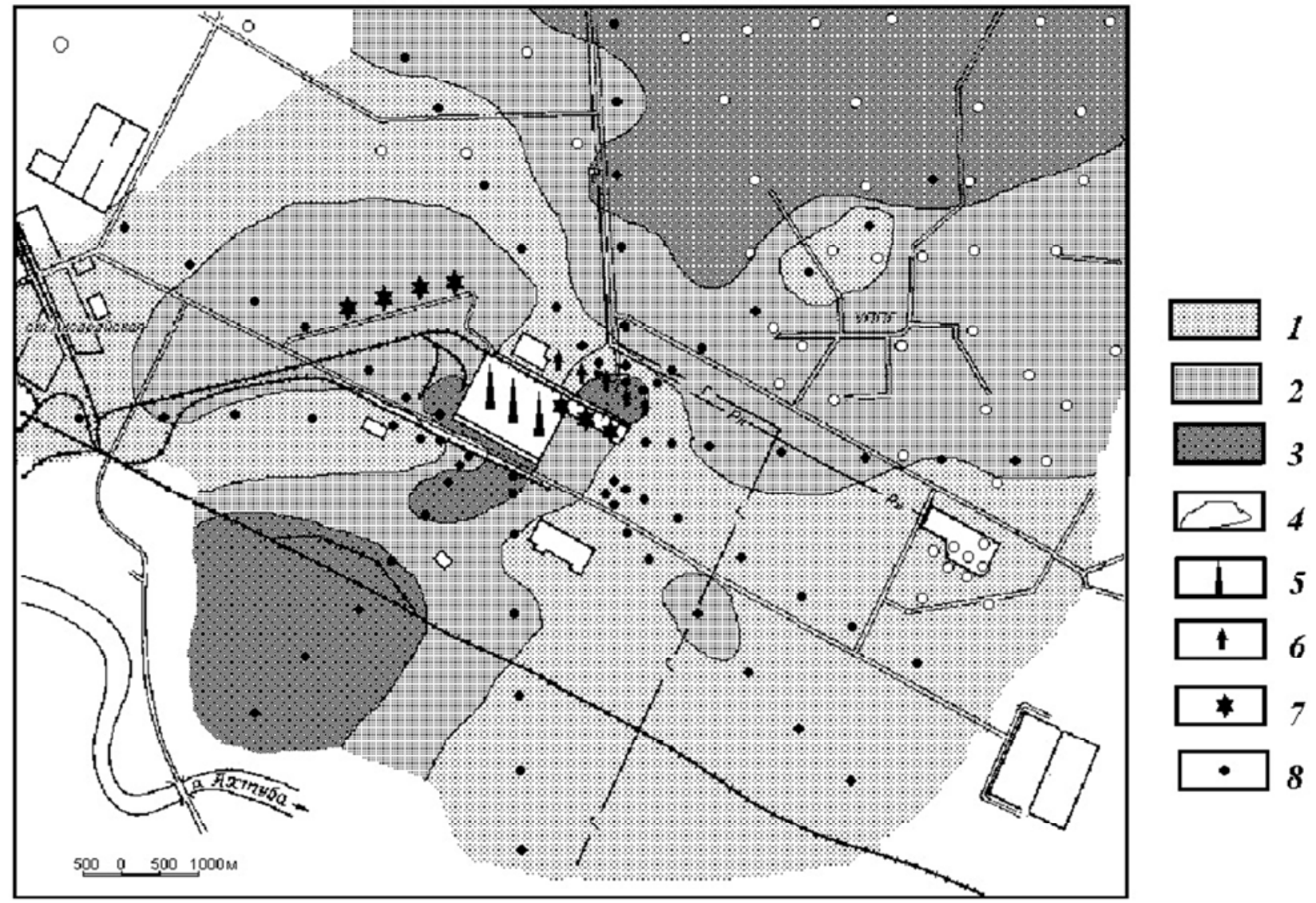

Figure 3. MERCURY in Soils of the Near Zone of Control AGC-0-5 km in 2007, $\mathrm{mcg} / \mathrm{kg}$.

1, 2 and 3 - 20-70, 70-100 and 100-120, respectively; 4 - isolines of content, 5 and 6 - AGPP: high pipes (200-300 m) and high pressure flares, respectively; 7 open sulfur storage, 8 - sampling points of soils, 9 - wells of the drilling field. Rose of Wind, \%. 


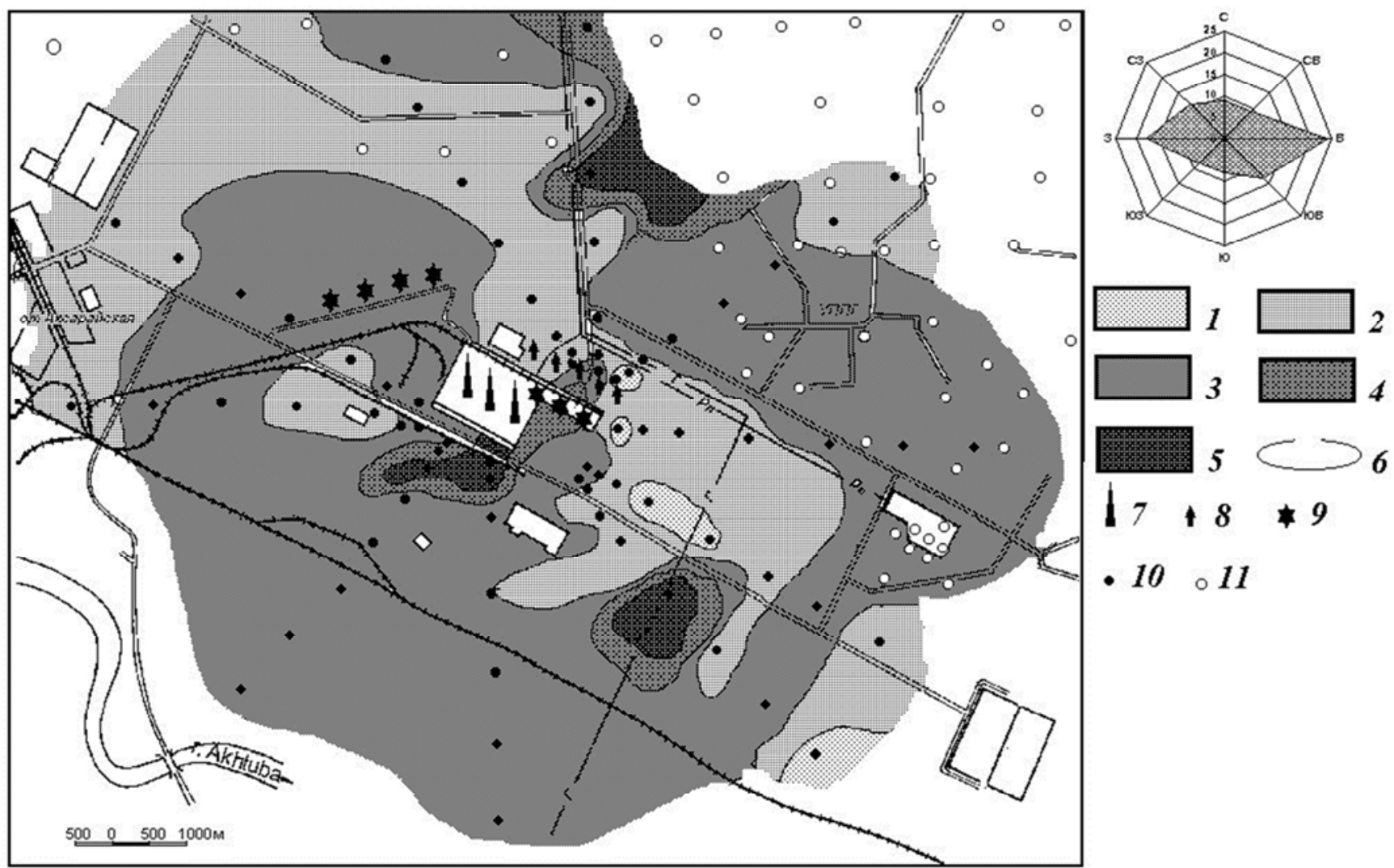

Figure 4. Dynamics of $\mathrm{Hg}$ in the soils AGC sanitary protection zone: accumulation-dispersion of concentrations in $1997\left(C_{1}\right)$ and $2007\left(C_{2}\right), K_{c} 10$.

Dynamics, $\mathrm{Kc}_{10}=\mathrm{C}_{2} / \mathrm{C}_{1}: 1$ (dispersion) $<1$ and 2, 3, 4, 5 (accumulation) - 1-3, 3-7, 7-15, 15-23, respectively; 6 - accumulation isolines $\mathrm{Kc} \mathrm{c}_{10}$; 7 and $8-$ pollutants emission sources: boiler-houses, Astrakhan Gas Complex (AGC) funnels and gas flares; 9 - depositories the sulphurs; 10 - soil samples collection points, 11 - wells. Rose of Wind, \%: 1989-2006 years period

\subsubsection{Mercury}

This particularly dangerous toxicant is paid close attention. $\mathrm{Hg}$ is contained in raw materials, products of its processing and emissions; accumulates in soils. In one of the points of the far control zone (AGC - 5-50 km), up to $285 \mu \mathrm{g} / \mathrm{kg}$ mercury (1997) was detected $[1,4,5]$ (table 1). The content almost reached the "target" safe concentration level (300 $\mu \mathrm{g} /$ $\mathrm{kg}$, adopted in Western Europe [12]).

Hg sources. Natural accumulation in the soils achieves 255 $\mathrm{mcg} / \mathrm{kg}$ in the interior draining-out of gases zones along the crust fractures. Industrial $\mathrm{Hg}$ - in the flue gas caused by burning wastes and sulphur production $\left(0.14-0.5 \mathrm{mcg} / \mathrm{m}^{3}\right)$; from the blowing of holes; from AGC solid wastes (up to 1 $\mathrm{mg} / \mathrm{kg}$ ); in the local production gasoline, diesel gas oil and fuel oil $(60 \mathrm{mcg} / \mathrm{kg})$; in the Donetsk coal $(20 \mathrm{mcg} / \mathrm{kg})$ used in the boiler-houses work; in oils, its derivatives and ashes $(0.02-0.03 \%$ or $200-300 \mathrm{mg} / \mathrm{kg})$. $\mathrm{Hg}$ sources may be territories cluttered up with solid wastes and residual concentration centers of extensive application of pesticides and solid inhibitors in the past $[1,4,13,14]$.

The monitoring of soils recorded atmospheric fluxes of heavy metals and $\mathrm{Hg}$. Samples of soils were selected only from the surface of the peaks of the hillocks, ridges and in the unsealed areas of the floodplain.

a) Backgrounds: The amount of $\mathrm{Hg}$ in the soils of the control areas for the whole monitoring period was stable $15-20 \mu \mathrm{g} / \mathrm{kg}$ (removal $\geq 50 \mathrm{~km}$ to NE from AGC).

b) Zones of control. The average $\mathrm{Hg}$ content over the entire near zone of AGC-50 km increased 5-fold during the 1991-2007 period. This was due to an increase in average concentrations by a factor of $343 \%$ of the area of this control zone (AGC -5 km: 5 samples - 14-22 times). In the far zone of control of AGC - (5-50) km by 2007 the $\mathrm{Hg}$ content gradually decreased by 1.9 times (Figures $1-5$, table 1,2 ).

Within a radius of $15 \mathrm{~km}$ from the AGC in the leeward northwestern territories (Aksaray, Dosang and other settlements), the average concentrations of $\mathrm{Hg}$ in soils over 10 years (1997-2007) increased 2.5 times more intensively (Dosang settlement: $\mathrm{Kc}=6.3$ ) than with mercury releases to the northeast (sands of Sorkuduk: Kc $=2.5$ ) (Figure 1).

In some parts of the floodplain, the amount of $\mathrm{Hg}$ decreased by $\geq 10$ times: from $225-285 \mu \mathrm{g} / \mathrm{kg}$ to $20 \mu \mathrm{g} / \mathrm{kg}$ (the districts of the rivers Rechnoy, Zavolzhsky, Raznochinovka, Teplinka, remote at $\geq 40 \mathrm{~km}$ from AGC). By the spring of 2012 the $\mathrm{Hg}$ content was fixed at the level of background values $(\leq 20 \mu \mathrm{g} / \mathrm{kg})$. This phenomenon can be associated with both laboratory errors in the determination of mercury and with differences in natural conditions during different sampling seasons (Figure 5; table 1). 


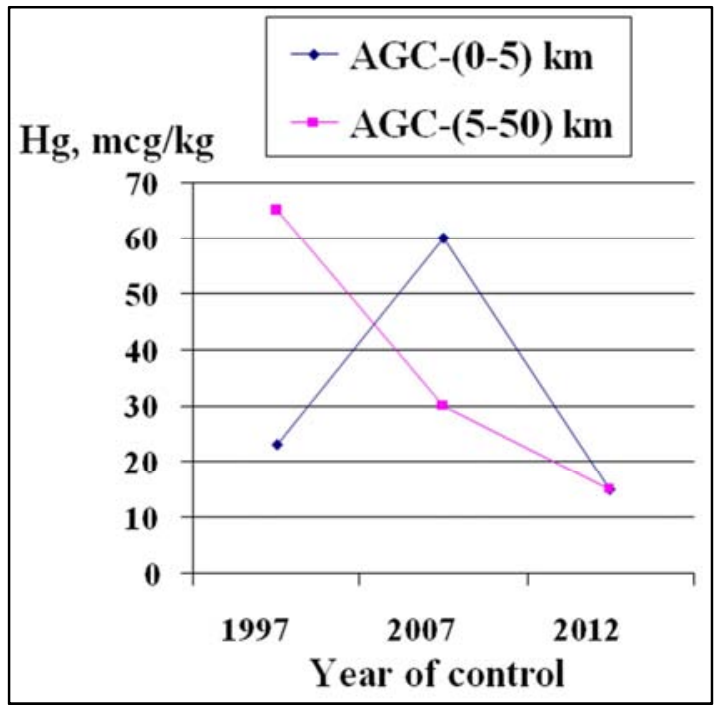

Figure 5. Dynamics of $\mathrm{Hg}$ in the soils $A G C$ sanitary protection zone: accumulation-dispersion of concentrations in $1997\left(C_{1}\right)$ and $2007\left(C_{2}\right), K c_{10}$ MERCURY in soil of near $A G C-(0-5) \mathrm{km}$ and remote $A G C-(5-50) \mathrm{km}$ of control zones: average content dynamics over the 15-year period 1997-2012, $\mathrm{mcg} / \mathrm{kg}$.
In this case, a regular phenomenon is confirmed: an increase in the concentration of $\mathrm{Hg}$ on the soil surface in the summer (2007) and a decrease in the metal content after snow melting and some self-cleaning of the soil (1997 and 2012).

An essential role in the deterioration of the hygienic state of the northwest territories belongs to the eolian factor. They are located nearby and leeward in relation to AGPP, as well as wells of the drilling field of the gas condensate field and open storage facilities for $\mathrm{Hg}$-containing commercial sulfur. When dealing with toxic sulfur, the transfer of its particles and their spacing in aerosols by the prevailing $\mathrm{E}$ and SE winds to the west and northwest from AGPP is intensified [1, $5,6]$. This process is evidenced by halos of accumulation of $\mathrm{Hg}$ in the area of storage, loading and transportation of sulfur, and wells of the drilling field (Figures 1, 3, 4).

\subsubsection{The Total Number of Metals}

The total number of metals in both the near and far zones and on the backgrounds (leeward and windward areas) increased over the 15 years of control (1997-2015) (Figures $2,6,8$; table 3 ).

Table 3. Background areas: long-term dynamics of total accumulation of metal in soils Zc(MnCrVNiCoCuAgZnPbSnMo).

\begin{tabular}{lll}
\hline \multirow{2}{*}{ Year of control* } & \multicolumn{2}{l}{ Values of Zc at background sites, 26-30 km from AGC } \\
\cline { 2 - 3 } & Windward, to NE & Leeward, to the NW \\
\hline 2007 & 1.7 & 7.2 \\
2012 & 8.0 & 12.9 \\
\hline
\end{tabular}

The ME concentration in 1997 was taken as the base level of the calculation of Zc

a) Backgrounds. In general, for the period 1997-2012 the values of $\mathrm{Zc}$ on backgrounds increased to $~ 8-13$ times: Ag, $\mathrm{Cr}, \mathrm{Zn}$ and $\mathrm{Pb}$ concentrations increased by 1.6-3.8 times, and the contents of $\mathrm{V}$ and $\mathrm{Mn}$ decreased by 1.2-1.4 times. Longterm accumulation of metals in the soil of the background leeward northwestern (NW) and windward northeastern (NE) sites led to the fact that for 15 years the total amount of heavy metals in the values of the indicator $\mathrm{Zc}$ (MnCrVNiCoCuAgZnPbSnMo) was equalized. The difference between their number in NE and NW sites by 2012 was substantially smoothed (Figure 6; table 1-3).

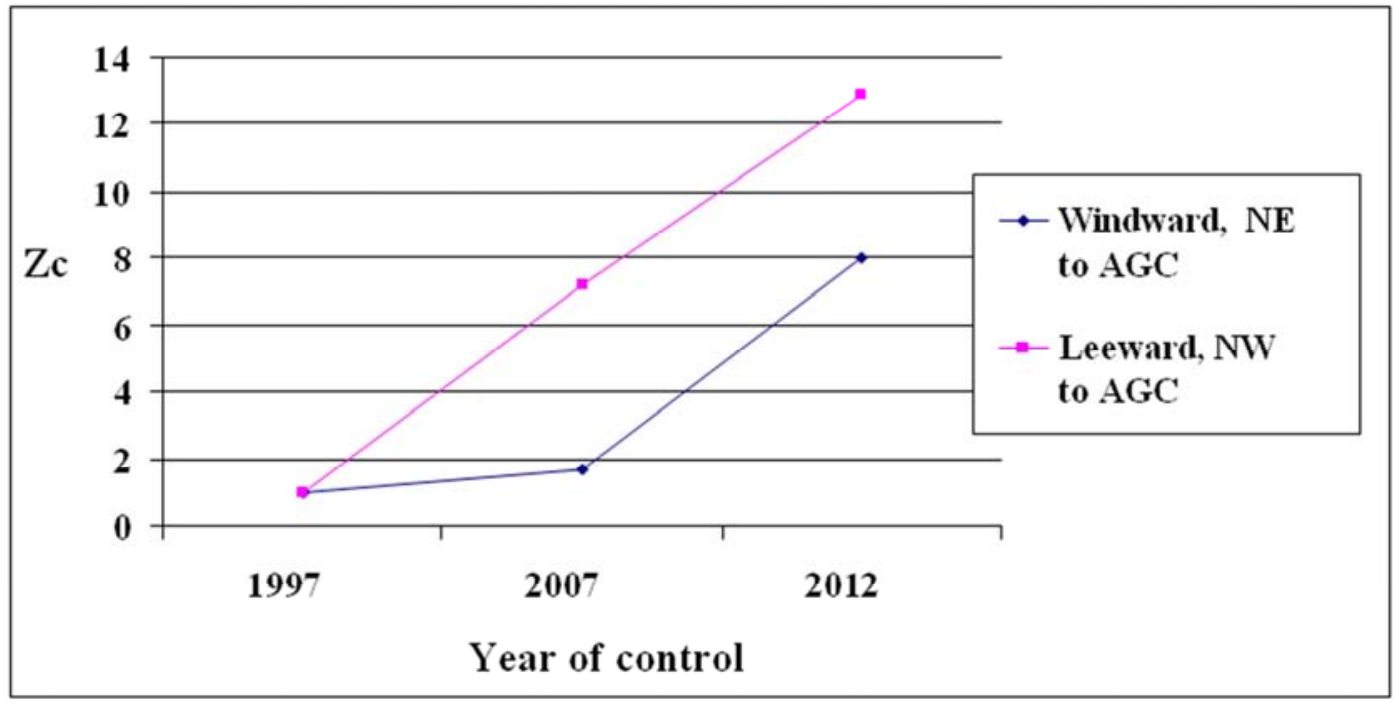

$\mathrm{Zc}(\mathrm{MnCrVNiCoCuAgPbSnMo})$ in soils

Figure 6. Background sites: long-term dynamics of accumulation of the sum of metals. 
Such deterioration of the hygienic state of the territories from the windward E and NE sides of the AGPP (both in the accumulation of $\mathrm{Hg}$ and other $\mathrm{HM}$ ) is possibly associated with routine annealing and blowing of dozens of wells at the drilling field. The work is carried out, mainly, at SW and W winds. The distribution of emissions towards populated areas in such wind directions is excluded.

However, the concentrations of HM from the windward sides remained lower than in the leeward areas. So, if in 2007 on the windward side the values of $\mathrm{Zc}$ were 4.2 times less than in leeward areas, then in 2012 they were only 1.6 times different from the amount of HM on leewards (Figure 7, table $1,2)$.

b) Zones of control. In the near zone of AGC-5 $\mathrm{km}$ for 5 years (2007-2012), the total accumulation of metals $( \pm \Delta \mathrm{Zc}=$ $\mathrm{Zc}_{2012}-\mathrm{Zc}_{2007}$ ) was diagnosed, on average, by the growth of the indicator: $+\Delta \mathrm{Zc}=+4.9$ (up to $+15,5$ ). This occurred at $85 \%$ of its area (62 of 73 samples). Scattering of HM was observed only on $\sim 14 \%$ of the area of the sanitary protection zone (SPZ: 10 samples, decrease of the indicator values: $\Delta \mathrm{Zc}=-3.0$ and to -6.4$)$.

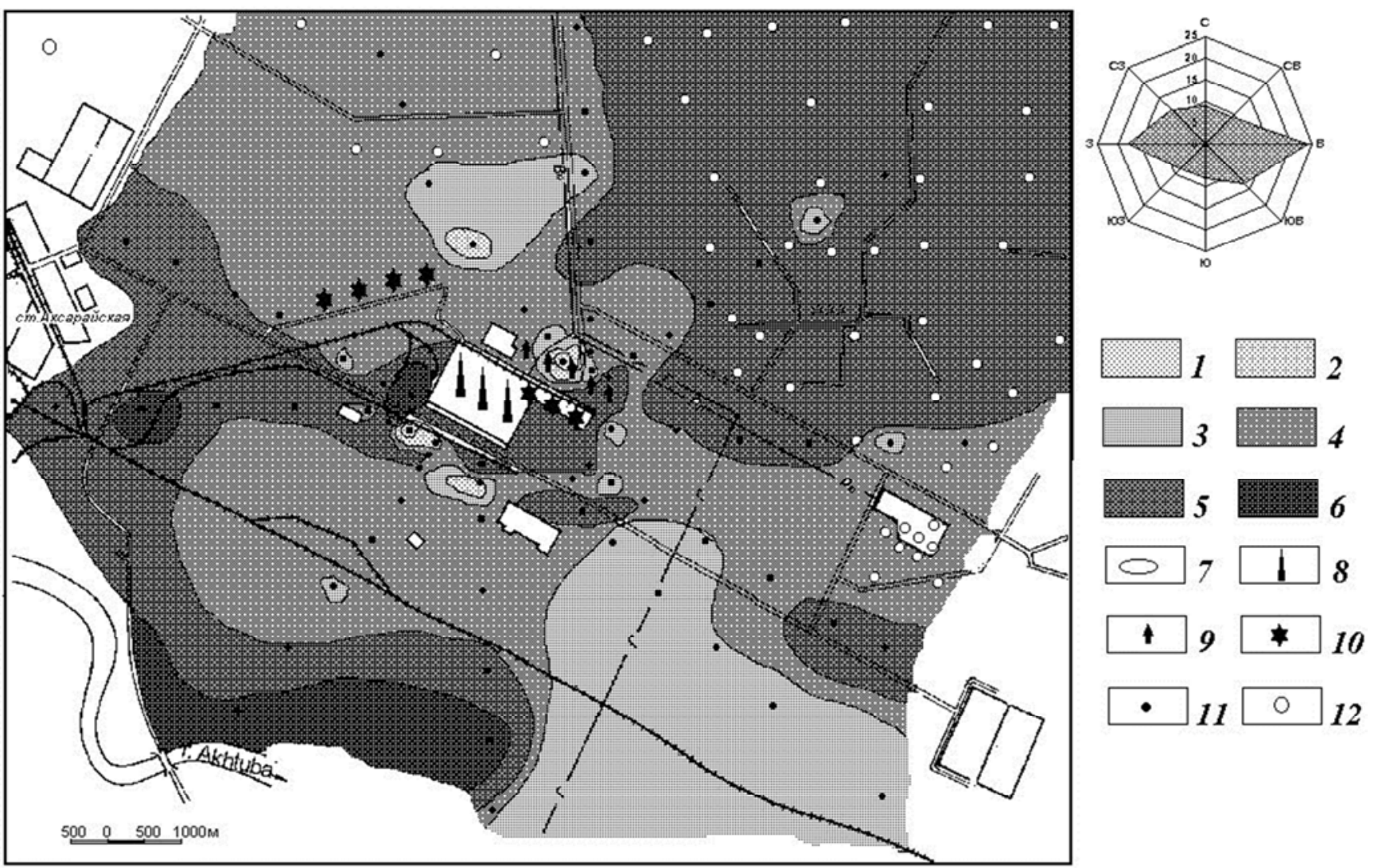

Figure 7. Dynamics of total soils contamination by metals AGC sanitary protection zone, 1997-2012 years period: $\pm \Delta Z c(M n C r V N i C o C u A g Z n P b S n M o)=$ $Z c_{(2012)}-Z c_{(1997)}$

1-6 - changing trends: differential $\Delta=Z_{c_{2007}}-Z_{c_{1997}}$ : 1 - stabilization or slight accumulation: 0-3; 2, 3, 4, 5 and 6- sustained accumulation: 3-6, 6-8, 8-10, 10-15 and 15-22, respectively; 7 - isolines of values $\pm \Delta$ Zc, including supposed (dotted line); 8 and 9 - pollutants emission sources: boiler-houses, Astrakhan Gas Complex (AGC) funnels and gas flares; 10 - depositorys the sulphurs; 11 - soil samples collection points, 12 - wells. Rose the winds, \%: $1989-2006$ years period

In 2007, moderately hazardous levels were recorded only at sites affected by local sources of pollutants. In April 2012, for the first time in the whole period of monitoring, in a number of places in the SPZ, pollution by the values of the indicator $\mathrm{Zc}$ (MnCrVNiCoCuAgZnPbSnMo) increased and reached already moderately dangerous (up to $\mathrm{Zc}=27.4$ ), and in the zone of AGC-5-25 km - levels (up to $\mathrm{Zc}=33.5$ ). Concentrations of $\mathrm{Pb}, \mathrm{Zn}$ and $\mathrm{Ni}$ increased 5-10 times, in contrast to the decrease in $\mathrm{Hg}$ content to background values (Figures 5, 8). 


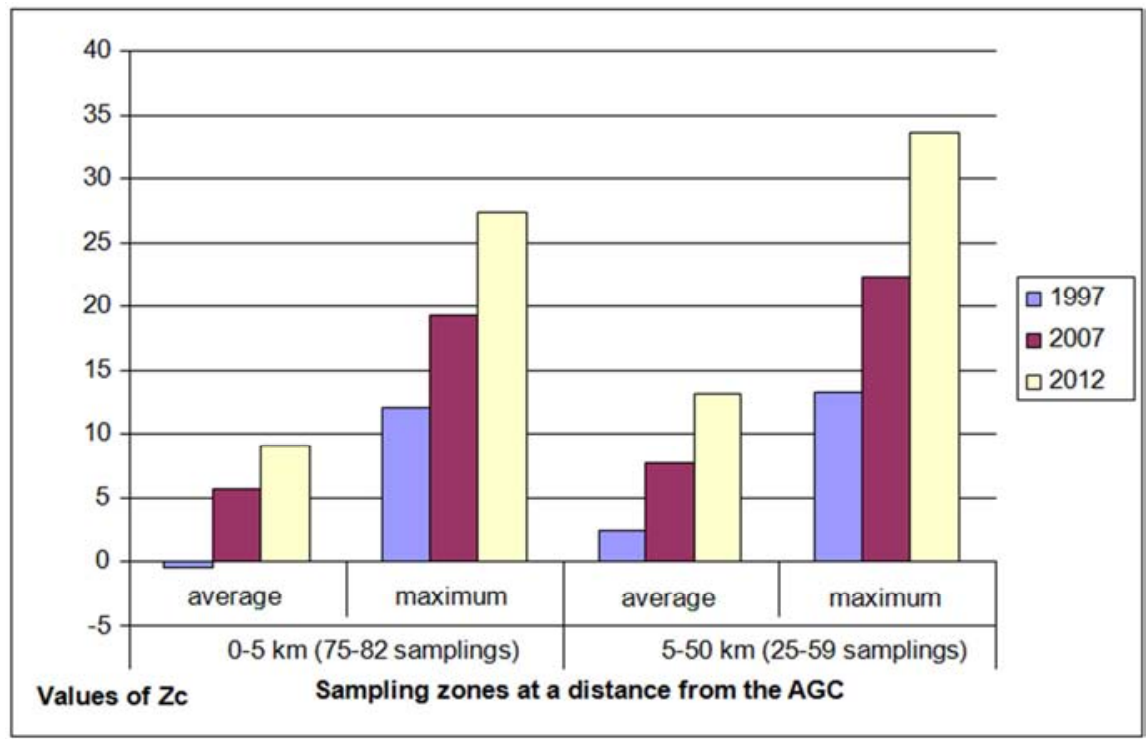

Figure 8. Decrease in hygienic quality of territories in the area of the AGC at the monitoring stages of 1997, 2007 and 2012. (15-year period): accumulation of the sum of heavy metals Zc (MnCrVNiCoCuAgZnPbSnMo) in soils (Background - HM content in 1997).

\subsection{Object No. 2}

Object urban-types settlements in Ikryaninsky District of Volga Delta on the coasts of major delta waterflow - the Bakhtemir branch (table 4). Flat relief includes the relics of sandy Baer knolls (up to 8-15 m high). Soils in the villages are generally anthropogenically changed. The Solonchaks contain conventional accumulations of waste. Gasification of populated areas is in process during last decades. Before the gasification numerous boiler-houses used coil and masut as fuel - the main industrial $\mathrm{Hg}$ sources. Natural $\mathrm{Hg}$ accumulation is virtually absent $[1,15]$.

The reliability of hygienic assessments of the condition of the territories is ensured by both the method and the observance of the same seasonality of soil sampling.

In 2009 the additional research of $63 \%$ of village territory (215 samples) was conducted (comparing to the work stage in 1995). The $\mathrm{Hg}$ dynamics trends were detected by calculation of the index $\tau$, \% (table 4).

Table 4. Comparative characteristics of Mercury concentration in the soils: Ikryaninsky District villages in the Volga river delta and the Moscow city blocks.

\begin{tabular}{|c|c|c|c|c|c|}
\hline \multirow{3}{*}{$\begin{array}{l}\text { Villages, number of } \\
\text { samples } \\
\text { (in 1995) }\end{array}$} & \multicolumn{4}{|l|}{$\mathrm{C}, \mathrm{mcg} / \mathrm{kg}$} & \multirow{3}{*}{ Changing: $\tau, \% *$} \\
\hline & \multicolumn{3}{|l|}{ April 1995} & \multirow[t]{2}{*}{ April 2009} & \\
\hline & range & average & Cont & & \\
\hline \multirow{4}{*}{ Ilyinka (88) } & \multirow{3}{*}{ 4.8-197 } & \multirow{3}{*}{33} & 197 & 20 & -90 \\
\hline & & & 95 & 20 & -79 \\
\hline & & & 92 & 20 & -78 \\
\hline & \multirow{4}{*}{$1.8-114$} & \multirow{4}{*}{31} & 60 & 20 & -67 \\
\hline \multirow{3}{*}{ Krasnye Barrikady (125) } & & & 75 & 30 & -60 \\
\hline & & & 60 & 20 & -60 \\
\hline & & & 114 & 20 & -83 \\
\hline \multirow{7}{*}{ Ikryanoe (168) } & \multirow{7}{*}{$1.2-122$} & \multirow{7}{*}{34} & 112 & 40 & -64 \\
\hline & & & 98 & 20 & -80 \\
\hline & & & 122 & 20 & -84 \\
\hline & & & 82 & 20 & -76 \\
\hline & & & 107 & 20 & -81 \\
\hline & & & 104 & 20 & -81 \\
\hline & & & 84 & 20 & -76 \\
\hline \multirow{4}{*}{ Bakhtemir (76) } & \multirow{4}{*}{$1.8-212$} & \multirow{4}{*}{35} & 212 & 20 & -91 \\
\hline & & & 145 & 30 & -79 \\
\hline & & & 92 & 20 & -78 \\
\hline & & & 81 & 60 & -26 \\
\hline \multirow{3}{*}{ Trudfront (65) } & \multirow{3}{*}{$6-316$} & \multirow{3}{*}{49} & 100 & 30 & -70 \\
\hline & & & 316 & 50 & -84 \\
\hline & & & 6 & 30 & +400 \\
\hline \multirow{3}{*}{ Moscow } & $230-3250$ & 720 & \multicolumn{3}{|c|}{ Block in Lefortovo district, 300 x $500 \mathrm{~m}$ square, October 1999, 32 samples } \\
\hline & $30-1600$ & 120 & \multirow{2}{*}{\multicolumn{3}{|c|}{ Proletarsky prosp. - Kashirskoye shosse, November 2006, 124 samples }} \\
\hline & $50-1930$ & 110 & \multicolumn{2}{|c|}{ Balaklavskiy prosp. - industrial zone «Kotlyakovo», June 2007, 147 samples } & \\
\hline
\end{tabular}

$\tau, \%=\left[\left(\mathrm{Kc}_{2} / \mathrm{Kc}_{1}\right) \times 100\right]-100$ : it fixes the Hg concentration change in 2009 relative to basic amount of metal in $1995 ; \mathrm{C}-$ number, mcg $/ \mathrm{kg} ; \mathrm{Kc}-\mathrm{element}$ concentration criterion relative to background $\left(\mathrm{C} / \mathrm{C}_{\text {backgr }}\right) ; \mathrm{C}_{\text {backgr }}=6 \mathrm{mcg} / \mathrm{kg}[1,15]$ 
In 1995 in some tests up to $114-316 \mathrm{mcg} / \mathrm{kg}$ of $\mathrm{Hg}$ was found out. Refocusing of boiler-houses to natural gas and reduction of pollutant emissions including $\mathrm{Hg}$ wastes caused the enhancement of urban territories: up to $91 \%$ of $\mathrm{Hg}$ dispersed by 2009 ; toxic concentration decreased to $20-60$ $\mathrm{mcg} / \mathrm{kg}$ over 15 years.

\subsection{Current State of the Problem}

It is important to note again that in recent years such detailed monitoring of HM in soils on the lands of the region is not carried out.

Currently, the main attention is paid to the quality of atmospheric air. The observations are characterized by a rare network of control points of Rospotrebnadzor in Astrakhan and in the largest settlements of The region, as well as sectoral monitoring at the borders of the sanitary protection zone the AGC. Among the controlled ingredients $\mathrm{SO}_{\mathrm{x}}, \mathrm{NO}_{\mathrm{x}}, \mathrm{CO}_{\mathrm{x}}, \mathrm{H}_{2} \mathrm{~S}$ and some hydrocarbons are in the lead. Very little attention is paid to metals (mainly $\mathrm{Pb}$ ). On the basis of this kind of information, attempts are made to assess the relationship between air quality and human health [16-18].

The level of chemical contamination of soils is also estimated by a very limited range of ingredients in some points of the state network of environmental monitoring [16]. Technologies of land quality assessment and study of poorly investigated phenomena of human ecological pathology foci are based on previously obtained data on chemical soil pollution - the most representative in its detail and breadth of coverage of the territories [17, 19-21].

\section{Conclusion}

The hygienic condition of most of the territory at a distance of up to $30 \mathrm{~km}$ from the AGC since the start of operation of the AGPP has been deteriorating. This is evidenced by the results of long-term monitoring of heavy and toxic metals in soil (1991-2012).

$\mathrm{Hg}$ concentration in research soils was lower than sanitary requirement criterion in Russia $(2.1 \mathrm{mg} / \mathrm{kg})$, but in some places it was near or more than safe-level of famous Holland list $(0.3 \mathrm{mg} / \mathrm{kg})$.

The total amount of metals in 2012 in a number of foci of concentration has reached already dangerous levels of $\mathrm{Zc}$ $(\mathrm{MnCrVNiCoCuAgZnPbSnMo})=27-34$. Their accumulation occurs even on backgrounds and especially progresses in the sanitary protection zone. This phenomenon is mainly due to the impact of low-emission sources, including routine well blow-outs and wind-blown Hg-containing sulfur.

Tendencies of long-term dynamics of $\mathrm{Hg}$ and other $\mathrm{HM}$ concentrations are controlled by the direction of prevailing winds, terrain relief and sorption capacity of soils. Inconstancy and technical nature of work of industrial sites as pollutant sources play significant role in this dynamics. Improvement of the technology of gas condensate production and processing, elimination of the release of $\mathrm{HM}$ into the environment as a part of emissions of boiler houses for liquid and solid fuels, gasification of populated areas provided natural cleansing of soils from $\mathrm{Hg}$ to $91 \%$ of the area of settlements in the Volga delta in the Astrakhan region for 15 years.

The specific medical statistics on the certain settlements and iterated soil sample collection are necessary for specification of pollution dynamics and diagnostics of hygienic condition of studied lands.

\section{References}

[1] Bogdanov N. A. Ecological zonation: scientific and methodic practice (Astrakhan Region). - Moscow: Editorial URSS, 2005. - P. 1-176. (in Russian).

[2] Sanitation-and-epidemiological requirements to soil quality. Sanitary regulations and standards (SanPiN) 2.1.7.1287-03.Moscow: Ministry of Health of the Russian Federation, 2003. - P. 1-18. (in Russian).

[3] Bogdanov N. A. Sanitary-hygienic evaluation territory of Astrakhan. Proc .: Caspian - Present and Future: Proceedings of the international conference. Astrakhan on 16-17 november 1995. Astrakhan: ITA "Interpress", 1995; 235-237. (in Russian).

[4] Bogdanov N. A. Mercury and other toxic metals in soils indicator of sanitary state of territories: Astrakhan region // The problems of biogeochemistry and geochemical ecology. 2013; 2(23): 24-31. (in Kazakhstan).

[5] Bogdanov N. A. Long-term dynamics of mercury in the landscapes of the Caspian: soil Astrakhan region. Proc : Mercury in the biosphere: ecological and geochemical aspects. Proceedings of the International Symposium. Moscow, 7-8 September 2010. M.: GEOHI RAN, 2010; 177-182. (in Russian).

[6] Bogdanov N. A., Pishchulov S. A. Geotehsistema serohranilisch as part of the Astrakhan gas complex // Regional environmental issues. 2013; 2: 5-12. (in Russian).

[7] Velikanov E. B., Chuykov Yu. S. On the environmental situation in the area of Astrakhan gas condensate field (report at a meeting of the Environmental Parliament Volga basin, Nizhny Novgorod, September 16, 1991) // Astrakhan Herald of ecological education. 2014; 4 (30): 192-200. (in Russian).

[8] Krasnov I. O., Chuykov Yu. S., ed. State report on the environmental situation in the Astrakhan region in 2013. 2014. 195 s. Available at: nat.astrobl.ru. (in Russian).

[9] Borzyih M. N. Problems of mercury pollution and recycling of mercury-containing wastes. In $2 \mathrm{kN}$. M: Publishing house "Arms and technologies"; 2008; Vol. 1: 368. (in Russian).

[10] Panin M. S. Environmental contamination: The textbook, edited by I. O. Baitulin. Almaty: Rarity, 2011; 668. (in Kazakhstan).

[11] Ingel F. I., Legostaeva T. B., Antipanova N. A. and others. System for identifying potentially carcinogenic compounds, the priority for hygienic in the air // Hygiene and sanitation. 2012; 6: 33-36. (in Russian). 
[12] Bessonov V. V., Yanin E. P. Methods of assessment and remediation of mercury contaminated urban soils. In the book: Mercury. Problems of Geochemistry, ecology, Analytics. M.: IMGRE; 2005; 160-180. (in Russian).

[13] Ozerova N. A., Ryzhov V. V., Mashyanov N. R. and others. Hydrargyrum-bearing capacity of the Astrakhan gas condensate field (theoretic and applied issues) // Oil and gas genesis. - Moscow: GEOS, 2003. - P. 232-240. (in Russian).

[14] Sudo M. M., Sudo R. M. Oil and hydrocarbon gases in modern world. Second publication, update. - Moscow: LKI Pub. House, 2008. - P. 1-256. (in Russian).

[15] Bogdanov N. A., Barmin A. N., Iolin M. M. Soil microelement composition analysis in diagnostics of inconstancy of urban territories conditions // Regional environmental issues. - № 4. - 2011. - PP. 76-82. (in Russian),

[16] On the state of sanitary and epidemiological welfare of the population in the Astrakhan region in 2016: State report. Astrakhan: office of Rospotrebnadzor for the Astrakhan region, 2017. - 213 p. (in Russian).

[17] Rybkin V. S., Chuikov Yu. S., Kolomnin V. V., Teplaya G. A., Vavilina A. V. Environmental problems and health status of the population in the Astrakhan region // Astrakhan Herald of ecological education. 2016; 1 (35): 36-41. (in Russian).
[18] Kolomnin V. V., Rybkin V. S., Chuikov Yu. S. Integrated approach to hygienic control of air quality in populated areas // Astrakhan Herald of ecological education. 2018; 1 (43): 5159. (in Russian).

[19] Bogdanov N. A. Ecochemical geomorphology - a new direction in the science of relief // Astrakhan Herald of ecological education. 2015; 2 (32): 36-53. (in Russian).

[20] Bogdanov N. A. Hygiene and ecochemical geomorphology: the relationship in the framework of quality assessments of sanitary and epidemiological situations // Environmental problems of our time: identification and prevention of adverse effects of anthropogenic determinants and climate change on the environment and public health // Materials of the International Forum of the Scientific Council of the Russian Federation on human ecology and environmental hygiene (on the basis of fgbi "CSP" Ministry of health of Russia 14-15 December 2017, Moscow) // ed. RAS Yu. a. Rakhmanin. The Ministry of health of the Russian Federation, OMN RAS. - M.: NII Echigo them. A. N. Sysina. - 2017. - P. 54-57. (in Russian).

[21] Bogdanov N. A. Technology of estimation of the state of land by normalization of mercury by relation of its thermoform in the lithosubstrate // Astrakhan Herald of ecological education. 2018; 1(43): 4-19. (in Russian). 